\title{
Prize Sharing in Collective Contests
}

\author{
Shmuel Nitzan \\ Kaoru Ueda
}

CESIFO WORKING PAPER NO. 3212

CATEgory 2: Public CHOICE

OCTOBER 2010
An electronic version of the paper may be downloaded
- from the SSRN website:
www.SSRN.com
- from the RePEc website:
- from the CESifo website:
www.RePEc.org
www.CESifo-group.org/wp




\title{
Prize Sharing in Collective Contests
}

\begin{abstract}
The characteristics of endogenously determined sharing rules and the group-size paradox are studied in a model of group contest with the following features: (i) The prize has mixed private-public good characteristics. (ii) Groups can differ in marginal cost of effort and their membership size. (iii) In each group the members decide how much effort to put without observing the sharing rules of the other groups. It is shown that endogenous determination of group sharing rules completely eliminates the group-size paradox, i.e. a larger group always attains a higher winning probability than a smaller group, unless the prize is purely private. In addition, an interesting pattern of equilibrium group sharing rules is revealed: the group attaining the lower winning probability is the one choosing the rule giving higher incentives to the members.
\end{abstract}

Keywords: collective contest, mixed public-good prize, endogenous sharing rules, the groupsize paradox.

\author{
Shmuel Nitzan \\ Department of Economics \\ Bar Ilan University \\ Ramat Gan, 52900 \\ Israel \\ nitzans@mail.biu.ac.il
}

\author{
Kaoru Ueda \\ Faculty of Economics \\ Nanzan University \\ Nagoya, Aichi 466-8673 \\ Japan \\ k-ueda@nanzan-u.ac.jp
}

We are very much indebted to two anonymous referees and an associate editor for their most useful suggestions. 


\section{Introduction}

Many kinds of public decisions determine allocations of economic rents among various groups in society. The groups of possible beneficiaries try to make the allocations favorable to them through lobbying. Some important cases of such “interest-group politics" can be described as contests for a prize. A typical example is a choice of location for public facilities with positive externalities to the chosen locality (e.g., special economic zones, agricultural experiment stations, a stadium for the Olympic games and so on). The residents of the candidate regions expend time and money to appeal relevant politicians and bureaucrats for winning the prize associated with the selection of their region. Competitions for earmarked subsidies by local governments, conflicts in trade politics by industry groups, and ethnic conflicts within a country could also be modeled as such collective contests ${ }^{3}$. The main objective of this paper is to examine how endogenous "group sharing rules" in collective contests affect the validity of the "group size paradox." Let us briefly explain the terms in the quotation marks.

An important feature of interest-group politics is that individuals attain or lose the rent as a group, i.e. the winning of the rent is a "collective good". The benefit is shared in a group, which tempts individual members to free ride on the contribution by others. As Olson (1982) argues, how to manage such a collective-action or freerider problem is an essential factor to understand the existence, nature and effectiveness of interest groups. He particularly emphasizes that the larger the number of individuals or firms sharing a collective good, the smaller the gains they can expect from contribution to the group interest. Hence, "the incentive for group action diminishes as group size increases, so that large groups are less able to act in their common interest than small ones ${ }^{4}$." This famous conjecture is called the group size paradox by Esteban and Ray (2001).

As a device to manage the collective action problem, Olson emphasizes the "selective incentives," which are the incentives applied selectively to the individuals depending on their actions. In a collective contest, how to share the prize plays a critical role in providing such incentives. Studies of collective contests on privategood prizes have considered alternative ways of prize division among the members of

\footnotetext{
${ }^{3}$ On possible applications of contest models, see Konrad (2009). Epstein and Nitzan (2007) examine how the games of interest-group politics can be treated as contests. Esteban and Ray (2010) apply a contest model for studying ethnic conflicts.

${ }^{4}$ Olson (1982), p.31.
} 
the winning group. One possibility is that, prior to the contest, members of a group commit to a group sharing rule ${ }^{5}$. To study this type of collective contests, Nitzan (1991) focuses on a class of such rules that consists of linear combinations between the egalitarian and the relative effort sharing rules. In this case, part of the prize is divided equally among the group members (according to the egalitarian rule) and the rest is divided proportionally according to the members' efforts (according to the relative effort rule), which works as a selective incentive ${ }^{6}$. Lee (1995) and Ueda (2002) examine the endogenous determination of group sharing rules that belong to this class.

While much progress has been made in the study of prize sharing in collective contests for a private-good prize, the validity of the group size paradox has been questioned in collective contests for a public-good prize. Actually, as Chamberlin (1974) has pointed out, how much each member's gain decreases as the group gets larger depends on the degree of the rivalry in the consumption of the collective good. Katz, Nitzan and Rosenberg (1990) and Riaz, Shogren and Johnson (1995) examine the case where the prize is a pure public good for each group ${ }^{7}$ showing that, in this setting, a group with larger membership attains a winning probability larger than or equal to that of a smaller group. The group size paradox is not valid in such cases. In an important extension, Esteban and Ray (2001) study collective contests with a mixed private-public-good prize; part of the prize is a public good and part of the prize is a private good. They have been able to derive a rather moderate sufficient condition ensuring that a larger group attains a higher winning probability, and insisted that the group size paradox holds only in narrow cases.

The criticism by Esteban and Ray could have important implications for interest-group politics. We can interpret several rents sought by interest groups as a mixed prize. The object in regional, community or government division contests is often some budget, part of which can take the form of monetary transfers while the

\footnotetext{
5 Katz and Tokatlidu (1996), Wärneryd (1998) and Konrad (2004) consider another possibility; the division of the prize is determined by the within-group contest, subsequent to its award to the winning group. A third possibility is that the prize is utilized as a group-specific commons open to all members of the winning group. See Nitzan and Ueda (2009).

${ }^{6}$ This class of group sharing rules has an alternative interesting interpretation. As argued by Baik (1994) and Baik and Lee (2001), it can be interpreted as a "winner-help-loser" agreement, or a self insurance device applied by the groups.

7 Ursprung (1990) provides an interesting application of this kind of collective contests to a twocandidate electoral competition. For another approach which applies all-pay auction to a contest for a public-good prize, see Baik, Kim and Na (2001).
} 
rest must be used to supply some local public goods ${ }^{8}$. When a local government wins a contested subsidy earmarked for some public undertaking, part of it can be provided as an extra margin for the employed local people. Even an electoral competition can be conceived as a contest on a prize with mixed private-public good components, because a winning candidate is typically committed to the provision of both public and private benefits to his supporters ${ }^{9}$. Furthermore, if members of the winning group jointly taste the delight of victory, any group contest for a private-good prize could be actually that for a mixed prize.

In the Esteban-Ray model, however, it is postulated that the private part of the prize is equally divided among the members of the winning group. As argued above, the private-good prize can be utilized as a source of selective incentives. If such incentives play an important role for real interest groups confronting the collective action problems, it is essential to examine how the introduction of endogenous group sharing rules to contests for impure public goods affects the advantage of group size. By using a generalized version of the Esteban-Ray model, we will show that endogenous determination of a linear group sharing rules completely eliminates the group-size paradox, i.e. a larger group always attains a higher winning probability than a smaller group, unless the prize is purely private. The introduction of endogenous group sharing rules into collective contests for an impure public good prize dissolves the group size paradox, which has already been restricted by Esteban and Ray. Furthermore, we will provide a sufficient condition for a larger group to always get a higher per capita utility than that of a smaller group.

Our model also reveals an interesting pattern of equilibrium group sharing rules chosen by heterogeneous groups maximizing their per capita utility: if two competing groups have the same size, the group attaining the higher winning probability is the one that affords to use a more egalitarian group sharing rule, i.e. the rule divides a larger part of the prize according to the egalitarian rule. We can further identify the cases in which a larger group can choose a more egalitarian group sharing rule due to its group size advantage. This result seems strange on first glance, because the larger the part of the prize divided according to the relative effort rule, the

\footnotetext{
${ }^{8}$ See Nitzan (1994).

9 We could also conceive the prize in R\&D contests as such a mixed prize, because the winning R\&D team gets improved reputation (the status and recognition associated with the winning, which can be equally shared by all group members) and monetary benefits (the profit associated with winning the contest, that can be shared equally or not-equally by some or by all members).
} 
stronger the selective incentives and, in turn, the higher the winning probability of the group. As Sen (1966) has pointed out, however, the relative effort sharing rule can induce too much effort from the members of a group to attain a Pareto-efficient outcome (for the group). The maximization of the group's winning probability differs from the maximization of the group's welfare. When some groups are inferior to others in their ability to secure the prize, they have to assign a higher weight to the relative effort rule, to compensate for their disadvantage.

The next section presents our extended model of collective contests. Section 3 contains the result on the disappearance of the group size paradox. Section 4 presents the basic relationship between the characteristics of a group and its selected sharing rule. Some concluding remarks appear in Section 5. All proofs are relegated to Section 6.

\section{A Model of Group Contests for an Impure Public Good Prize}

\section{(a) Prize, Benefit and Cost.}

Let us consider a contest in which $m$ groups compete for a prize. The number of members in group $i$ is denoted by $N_{i}(i=1, \ldots, m)$. We assume that the prize is a mixture of public and private goods. That is, a winning group gets some groupspecific public goods and private goods that can be shared among its members.

For simplicity, we assume that every member of every group applies the same benefit function $B(q, G)$ to evaluate the prize, where $q$ is the amount of the private good distributed to the individual and $G$ is the amount of group-specific public good provided to the group to which the individual belongs. This function is twice differentiable, and $B(q, G)>0$ unless $(q, G)=(0,0)$. Furthermore, $B_{q}>0, B_{G} \geq 0$, and $B_{q q} \leq 0$ hold for all $q>0, G>0$. The CES benefit function $B(q, G)=\left(b_{1} q^{\rho}+b_{2} G^{\rho}\right)^{\frac{1}{\rho}}$ with $0<b_{1}<1,0<b_{2}<1$ and $\rho \leq 1$, satisfies these conditions. We will refer to this useful special case later.

We normalize the total prize to unity, and denote the ratio of the private-good part by $\gamma(0<\gamma \leq 1)$. That is, the model covers all prize compositions but the pure public-good case. The ratio is given exogenously. We assume that, prior to the contest, the rule applied for sharing the private part of the prize is determined in each group. This rule is assumed to be chosen from the class of sharing rules that are linear combinations of the egalitarian and the relative-effort sharing rules. Denote the weight 
of the relative-effort rule in group $i$ by $\delta_{i}$. Then, if group $i$ wins the contest, a member of the group having put effort $a \geq 0$ receives the benefit

$$
B\left(\gamma \cdot\left(\delta_{i} \cdot \frac{a}{A_{i}}+\left(1-\delta_{i}\right) \cdot \frac{1}{N_{i}}\right), 1-\gamma\right),
$$

where $A_{i}$ is the aggregate amount of effort put by the members of group $i$.

Every member of group $i$ incurs the cost $v_{i}(a)$ when making an effort equal to $a$ while trying to win the prize. The cost function is the same among the members of a group, but it can differ across the members in different competing groups. For every $i$, let $v_{i}(0)=0, v_{i}^{\prime}(a)>0$ and $v_{i}^{\prime \prime}(a) \geq 0$ for all $a>0$. To guarantee that every individual chooses a positive effort in equilibrium, we also assume that $\lim _{a \rightarrow 0} v_{i}(a)=0$.

\section{(b) The Structure of the Contest.}

Our model of group contest proceeds as follows. At the beginning, the decision on the value of $\delta_{i}$, i.e. the group sharing rule of the private-good part of the prize, is made simultaneously in each group. We assume that this decision is made (and implemented after the winning) by a group leader who maximizes a group welfare function strictly increasing in the utility of every member of the group. Such maximization ensures the selection of a Pareto-efficient group outcome, constrained by the contest with the other groups. Our assumption on such a benevolent objective of a leader could be (at least partially) justified if the intrinsic objective of a leader is the position itself, and the assignment of this position requires the consensus of the group members. After observing the sharing rule chosen by his group leader, each member in the competing groups described in the previous subsection, chooses the effort level individually.

At this point, we introduce a departure from the standard models of collective contests with predetermined group sharing rules: following Baik and Lee (2007), we choose to assume that the individuals cannot observe the group sharing rules decided in the other groups. Former studies presume that each group's sharing rule is observable from the outside. The decision on a group sharing rule is, however, made within a group, and it is plausible to assume that such a decision is changeable

\footnotetext{
${ }^{10}$ This assumption rules out linear cost functions. The main reason for this assumption is to avoid cumbersome cases of "oligopolization," i.e., some groups put no effort in the contest. While many researches ignore such cases, they usually appear in models of group contests with linear costs. See Ueda (2002).
} 
secretly (from the point of view of members in the other groups). Without restrictive assumptions that decisions made within a group are transparent and detection of changes is easy, a model of group contests with observable group sharing rules is questionable in its reality. Furthermore, it introduces a complicating factor in the decisions of the competing groups; observable sharing rules work as strategic variables. A group sharing rule determines how strong the selective incentives in a group are. If a group has an observable sharing rule, its change affects the effort of the individuals in the other groups by changing their expectations on the effort level of the group in question ${ }^{11}$.

Hence we assume that the value of $\delta_{i}$ is unobservable from outside, i.e. it is private information for the members of group $i$, and avoid the above unrealism and suspect strategic effects. In our model, therefore, the contest under any configuration of group sharing rules cannot be a proper subgame: each player in the contest, as a member of one of the competing groups, cannot specify the payoff functions of players in the other groups, which depend on the unobservable group sharing rules. When making a decision on how much effort to make, each individual is required to infer the sharing rules in the other groups. We therefore apply the perfect Bayesian equilibrium notion, even though our model is not an incomplete information game.

Given the effort levels put by all individuals, the contest winning probability of group $i$ is determined by

$$
\pi_{i}=\frac{A_{i}}{\sum_{k=1}^{m} A_{k}}
$$

where $A_{k}$ is the total amount of effort made by the members of group $k$. Although we apply the common simple lottery contest success function, notice that our model allows heterogeneity in the contestants' effectiveness by allowing differences in the cost functions of the groups.

\section{(c) Equilibrium.}

We will use the pure-strategy perfect Bayesian equilibrium as a solution concept, with a regularity condition on the belief profiles. For simplicity, we assume that only pure strategies are available for each player. That is, we do not consider the possibility of

\footnotetext{
${ }^{11}$ In the field of industrial organization, the strategic effects of internal contracts between competing vertical structures have been mentioned. Whether the contracts are observable or not is considered as an important factor there. See Katz (1991).
} 
randomization in each information set. To explain our regularity condition, let us describe the beliefs in the information sets of the players in equilibrium. The decisions on the group sharing rules by the leaders are made simultaneously at the beginning of the game. For their information sets, therefore, the belief is trivial.

Consider the belief and the strategy of a group member making effort in the contest, say the $k$ th member of group $i$. The individual's information set can be indexed by a value of $\delta_{i}$ corresponding to his group sharing rule announced by the group leader at the beginning of the contest. It is impossible to distinguish among the nodes at which different sharing rules are chosen in other groups. A strategy of the member is, therefore, described as a function of $\delta_{i}$, which is denoted by $a_{i k}\left(\delta_{i}\right)$. This member's belief $\mu_{i k}$ with respect to the sharing rules of the other groups can be constructed, also depending only on the value of $\delta_{i}$. For each $\delta_{i}$, the value $\mu_{i k}\left(\delta_{i}\right)$ is a probability measure defined on $[0,1]^{m-1}$, the space of possible configurations of the sharing rules in the other groups, $\delta_{-i}=\left(\delta_{1}, \cdots, \delta_{i-1}, \delta_{i+1}, \cdots, \delta_{m}\right)$.

Pick a profile of the sharing rules $\delta_{1}{ }^{*}, \ldots, \delta_{m}{ }^{*}$ and individual decisions on effort, $\left(a_{j h}{ }^{*}\left(\delta_{j}\right), \mu_{j h}{ }^{*}\left(\delta_{j}\right)\right)$, for all $j=1, \ldots, m ; h=1, \ldots, N_{j}$, and $\delta_{j} \in[0,1]$. Let us specify the necessary conditions for the profile to be a perfect Bayesian equilibrium. In a general representation, the expected utility of the $k$ th member of group $i$ at the information set indexed by $\delta_{i}^{\prime}$ is calculated as

$$
\int \frac{A_{i}^{*}\left(\delta_{i}{ }^{\prime}\right)}{\sum_{j \neq i} A_{j}^{*}\left(\delta_{j}\right)+A_{i}^{*}\left(\delta_{i}{ }^{\prime}\right)} B\left[\gamma \cdot\left(\delta_{i}{ }^{\prime} \cdot \frac{a_{i k}^{*}\left(\delta_{i}{ }^{\prime}\right)}{A_{i}^{*}\left(\delta_{i}{ }^{\prime}\right)}+\frac{1-\delta_{i}{ }^{\prime}}{N_{i}}\right), 1-\gamma\right] \mu_{i k}^{*}\left(\delta_{i}{ }^{\prime}\right)\left(d \delta_{-i}\right)-v_{i}\left(a_{i k}^{*}\left(\delta_{i}{ }^{\prime}\right)\right),
$$

where $A_{j}^{*}\left(\delta_{j}\right)=\sum_{h=1}^{N_{j}} a_{j h}^{*}\left(\delta_{j}\right)$. At the information set indexed by $\delta_{i}^{*}$, which lies on the equilibrium path, the requirement of consistency considerably simplifies the belief, which has to satisfy $\mu_{i k}^{*}\left(\delta_{i}^{*}\right)\left(\left\{\delta_{-i}=\delta_{-i}^{*}\right\}\right)=1$. That is, the individuals must correctly infer the sharing rules in the other groups, given the strategies of the leaders.

Now, we can state our regularity condition for the equilibrium beliefs at the un-reached information sets. We say that the belief by the $k$ th member of group $i, \mu_{i k}{ }^{*}$, in a perfect Bayesian equilibrium is stable if

$$
\mu_{i k}^{*}\left(\delta_{i}\right)\left(\left\{\delta_{-i}=\delta_{-i}^{*}\right\}\right)=1 \text {, for all } \delta_{i} \neq \delta_{i}^{*},
$$

i.e., the individual believes that any deviation from the sharing rule in his own group is irrelevant to the decisions made in the other groups. In our model, it is very natural to require that $\mu_{j h}{ }^{*}$ is stable for all $j$ and $h$, because the determination of the group 
sharing rule is not observable from outside. Even if an individual is told an out-ofequilibrium sharing rule by the leader, there is no reason to believe that such a deviation affects decisions made in the other groups. Henceforth, we take such $a$ pure-strategy perfect Bayesian equilibrium with stable belief profiles as the solution concept of our model.

Let us say that group $i$ has an interior group sharing rule, if $0<\delta_{i}^{*}<1$ holds in equilibrium. Denoting the win probability of group $i$ by $\pi_{i}$, we can state the following characterization of equilibrium:

Proposition 1. (i) In a pure-strategy perfect Bayesian equilibrium with stable beliefs, every individual belonging to the same group chooses a symmetric equilibrium effort (of course, those belonging to different groups can choose different effort levels), and attains a symmetric utility level.

(ii) An interior equilibrium sharing rule of the private-good component of the prize of group $i$ is given by

$$
\delta_{i}^{*}=\frac{1-\pi_{i}}{\eta\left(N_{i}, \gamma\right)}
$$

where

$$
\eta\left(N_{i}, \gamma\right)=\frac{\partial}{\partial q} B\left(\frac{\gamma}{N_{i}}, 1-\gamma\right) \cdot \frac{\frac{\gamma}{N_{i}}}{B\left(\frac{\gamma}{N_{i}}, 1-\gamma\right)}
$$

is the elasticity of the benefit from the private part of the prize.

The proposition establishes that there exists a strong relationship between the winning probability and the endogenously determined share of the private part of the prize that is distributed according to the relative effort rule, as long as the sharing rule is interior. Notice that since the benefit function is concave with respect to the private part of the prize, we get that $\eta\left(N_{i}, \gamma\right) \leq 1$, with strict inequality unless the prize is purely private $(\gamma=1)$ and the benefit function is linear with respect to the private part of the prize. Proposition 1 helps us to confirm the following existence result.

Proposition 2. In our model of group contest, there exists a unique pure strategy perfect Bayesian equilibrium with stable belief profiles. 
Henceforth we concentrate on equilibria in which every group chooses an interior sharing rule of the private component of the prize, i.e., $0<\delta_{i}^{*}<1$, for all $i=1, \cdots, m$.

\section{Disappearance of the Group Size Paradox}

Esteban and Ray have provided a sufficient condition for a group with larger membership to attain a higher winning probability in equilibrium. They have also proved that per capita utility increases (decreases) with membership size when the prize is purely public (private). We will show that endogenous group sharing rules surprisingly sharpen and strengthen their results.

Let all members of the competing groups share the same cost function $v$. Following Esteban and Ray, we denote by $\alpha(a)$ the elasticity of the marginal cost,

$$
\alpha(a)=\frac{a \cdot v^{\prime \prime}(a)}{v^{\prime}(a)} .
$$

Also, let us pretend that the membership $N_{i}$ is a continuous variable and view the winning probability $\pi$ and the benefit elasticity $\eta$ as its continuous functions. The membership size viewed as a continuous variable will be denoted by $n$. The following result presents the condition that determines the relation between group size and the winning probabilities of competing groups.

Proposition 3. Suppose that all individuals share the same cost function $v$. Let $N$ and $N^{\prime}$ be two group sizes with $N<N^{\prime}$. Then the winning probability of an $N^{\prime}$-member group is larger than that of an $\mathrm{N}$-member group, if

$$
1>\max _{n \in\left[N, N^{\prime}\right]} \eta(n, \gamma)-\inf _{a \geq 0} \alpha(a) .
$$

A larger membership implies a smaller per capita private-good component of the prize. Confronting the smaller benefit, each member puts less effort. The extent of this incentive can be measured by $\eta\left(N_{i}, \gamma\right)$. On the other hand, the larger membership also implies lower individual's marginal costs at a given level of group effort, which induces more effort from each member. The extent of this second incentive can be measured by $\alpha\left(\frac{A_{i}}{N_{i}}\right)$. The term $\max _{n \in\left[N, N^{\prime}\right]} \eta(n, \gamma)-\inf _{a \geq 0} \alpha(a)$ can be interpreted as the difference between the strength of these two incentives. The smaller the term, 
the more probable that the effort made by the larger group (the $N^{\prime}$-member group) is larger and, consequently, its winning probability is higher. We can easily check that the sufficient condition derived by Esteban and Ray (2001) can be written as

$$
0>\max _{n \in\left[N, N^{\prime}\right]} \eta(n, \gamma)-\inf _{a \geq 0} \alpha(a),
$$

for our generalized model ${ }^{12}$. Comparing this inequality with inequality (5), it is clear that letting the group sharing rules be endogenous considerably weakens the requirement for the group size advantage.

Actually, allowing the endogenous determination of group sharing rules closes the lid on the group size paradox. As we have already pointed out, $\eta(n, \gamma)$ is always less than 1, unless the prize is purely private. It is therefore straightforward to verify that:

Corollary 1. In a contest for a mixed private-public good where $\gamma \neq 1$, a larger group always attains a higher winning probability.

That is, a larger size always enhances the winning probability of the group, provided that the prize is not a pure private $\operatorname{good}^{13}$.

We can also provide a sufficient condition for a (large) group to attain a higher per capita utility than the smaller groups even if the prize is not a pure public good for the winning group.

Proposition 4. Suppose that all individuals share the same cost function $v$, and $\inf _{a \geq 0} \alpha(a) \geq 1$. Let $N$ and $N^{\prime}$ be two group sizes with $N<N^{\prime}$. Then the per capita (expected) utility in an N'-member group is larger than that in an N-member group, if the winning probability of the former group is less than one half and $\max _{n \in\left[N, N^{\prime}\right]} \eta(n, \gamma)<\frac{4}{5}$.

When the number of competing groups is larger than two, the winning probability of a

\footnotetext{
12 The model of Esteban and Ray can be interpreted as the special case in which it is common knowledge that every group leader always chooses the pure egalitarian rule. Set $\delta_{i}=0$ for all $i$, derive the first-order condition for the members to put effort under this condition, and follow the similar procedure in their proof (Esteban and Ray (2001) Proposition 1). To surely eliminates the group size paradox, it is needed to require that $\inf _{a} \alpha(a)>1$, as they actually state in their Proposition $1-\mathrm{a}$.

${ }^{13}$ Even in such a case, the group size paradox is not valid when the benefit function is strictly concave.
} 
group is less than one half, at least unless it is the most advantageous group attaining the highest probability. For such groups, a larger size implies a higher per capita utility, provided that the elasticity of the marginal cost is sufficiently high and the elasticity of the benefit from the private part of the prize is sufficiently low ${ }^{14}$.

\section{Group Characteristics and Prize Sharing}

\section{(a) Determinants of Differences in Winning Probabilities.}

Equation (3) in Proposition 1 reveals a simple and interesting relationship between the preferred egalitarianism of a group and its winning probability: a group attaining a high winning probability $\pi_{i}$ prefers a highly egalitarian group sharing rule (i.e., a low value of $\left.\delta_{i}\right)$, provided that the value of $\eta\left(N_{i}, \gamma\right)$ is constant. The equation does not imply that either $\pi_{i}$ or $\delta_{i}$ is a cause of the other, because both of them are simultaneously determined in equilibrium. However, if we identify some group characteristics enhancing the group winning probability, using equation (3) we can see that they also enhance the degree of egalitarianism in sharing the prize. Such identification is accomplished in the next proposition.

Proposition 5. If two groups $k$ and $l$ have the same group size and the same effort cost function for the members, i.e. $N_{k}=N_{l}$ and $v_{k}=v_{l}$, then $\delta_{k}{ }^{*}=\delta_{l}{ }^{*}$ holds and these groups share the same winning probability and per-capita utility. Furthermore, if all competing groups are symmetric, then their common weight of the relative effort rule $\delta^{*}$ is given by

$$
\delta^{*}=\frac{1-\frac{1}{m}}{\eta(N, \gamma)} .
$$

Hence, if two groups choose different values of the weight of the relative effort sharing rule, they must be different either in their costs or in their membership size. The assignment of a larger weight to the relative effort rule is actually due to inefficiency or size disadvantage of the group. Complete reliance on the relative effort

\footnotetext{
${ }^{14}$ With the notation of Esteban and Ray (2001) and their linear specification $B(q, G)=M q+P G$, the condition $\max _{n \in\left[N, N^{\prime}\right]} \eta(n, \gamma)<\frac{4}{5}$ can be expressed as $\theta_{\min }>\frac{1}{5}$, or $\frac{\frac{M}{N_{\min }}}{4 P+\frac{M}{N_{\min }}}<\lambda \leq 1$, where $\theta_{\min }=1-\eta\left(N_{\min }, \gamma\right)$ and $\lambda=1-\gamma$ (the ratio of the public-good part of the prize).
} 
rule induces the members to make excessive efforts that prohibit the attainment of Pareto optimum, while reliance just on the egalitarian rule also results in an inefficient outcome (Sen (1966)). The egalitarian sharing rule causes free-riding in a group because each member's effort has a positive externality for the other members under this rule. On the other hand, if the members are rewarded for their relative effort, each member's effort has a negative externality for the others, and the result is an excessive group effort ${ }^{15}$. An advantageous group that can secure a higher winning probability has room to loosen up this negative externality (which is due to selective incentives), still providing enough utility gain to compensate for the reduction in the winning probability.

Proposition 5 also discloses (see equation (6)) the effect of the number of competing groups on the group sharing rules. When the number of the groups is large, each group uses more of the private prize to provide selective incentives to its members $\left(\delta^{*}\right.$ is increasing with respect to $\left.m\right)$.

\section{(b) Different Efficiency.}

We have identified possible causes of the difference in the winning probabilities of competing groups; differences in costs or group sizes. On the effect of cost differences among the competing groups, we can derive the following result ${ }^{16}$.

Proposition 6. Pick two competing groups $k$ and $l$ with the same number of members, say $N$. Let the members of group $k$ have lower marginal costs than those of members of group l. That is, $v_{k}{ }^{\prime}(a)<v_{l}^{\prime}(a)$ for all $a>0$. Then, in equilibrium, $\pi_{k}>\pi_{l}$, which implies (see equation (3)) that $\delta_{k}^{*}<\delta_{l}^{*}$. Also, the per capita utility is larger in group $k$ than in group $l$.

Proposition 6 can be applied to shed light on the role of differences in the valuation of the prize ${ }^{17}$ and in lobbying capability. To study the effect of variability in the evaluation of the prize, we modify the model by letting members of group $i$

\footnotetext{
${ }^{15}$ We owe this intuition to one of the anonymous reviewers.

16 Baik and Lee (2007) have shown, in their model of two-group contest with equal group membership and a pure private-good prize, that a more efficient group chooses a more egalitarian rule. Their result can be considered as a special case of this proposition.

17 The early arguments on the role of different valuations of the prize in the contests can be found in Hillman and Riley (1989).
} 
have the benefit function $w_{i} B(q, G)$, where $w_{i}>0$ is the augmenting factor. The decision by an individual with the benefit function $w_{i} B$ and the cost function $v_{i}$ is equivalent to that by someone with the benefit function $B$ and the cost function $\frac{v_{i}}{w_{i}}$. If $w_{k}>w_{l}$, therefore, Proposition 6 is applicable, pretending that the members of group $k$ have a lower marginal cost than those of group $l$. To study the effect of variability in the political influence or lobbying power of the individuals, we interpret $A_{i}$ as aggregate effort measured by an efficiency unit, and assume that each individual of group $i$ needs to make $e_{i} a\left(e_{i}>0\right)$ units of effort to produce the efficiency units $a$. Then the cost function has the form $v_{i}\left(e_{i} a\right)$ and differences in political capabilities can be transformed to differences in the marginal cost of effort across groups.

\section{(c) Different Group Sizes}

We have already discussed how group size enhances the winning probability of a group. But we need to introduce a reservation regarding the relationship between a large group size and a highly egalitarian group sharing rule, because $\eta$ also varies with group size in equation (3). Nevertheless, if $\eta(n, \gamma)$ is non-decreasing with respect to the number of group members $n$ (and if $\gamma \neq 1$ holds), then the sharing rule applied by a larger group is more egalitarian.

The CES family of benefit functions, $B(q, G)=\left(b_{1} q^{\rho}+b_{2} G^{\rho}\right)^{\frac{1}{\rho}}$, with $0<b_{1}<1$, $0<b_{2}<1$ and $\rho \leq 1$, is a convenient specification to illustrate cases that fit the above reservation. With this form, we get that

$$
\eta(n, \gamma)=\frac{b_{1} \cdot\left(\frac{\gamma}{n}\right)^{\rho}}{b_{1} \cdot\left(\frac{\gamma}{n}\right)^{\rho}+b_{2} \cdot(1-\gamma)^{\rho}} .
$$

Let $\gamma \neq 1$. If $\rho<0$, i.e. the public and the private parts of the prize are not good substitutes, we can see that $\eta(n, \gamma)$ becomes non-decreasing with respect to $n$, and indeed the larger the group, the higher its egalitarianism in sharing the prize.

\section{Concluding Remarks}

We have examined a model of a group contest for a mixed private-public-good prize, in which each group can choose a sharing rule to distribute the private part of the 
prize among its members. Our main findings are the following: When each competing group can choose its sharing rule,

(i) the larger a group, the higher its winning probability (at least unless the contested prize is a pure private good): the selective incentives provided by endogenous group sharing rules are sufficient to eliminate the group size paradox, and

(ii) strong incentives appearing in the sharing rule of a group are not a sign of its advantage, but rather of its disadvantage relative to the other groups.

The first finding suggests that the group size advantage is a normal outcome in a contest by well-organized interest groups. The free-rider problems may prevent the individuals from organizing a large interest group. However, once somehow it is established and equipped with adequate selective incentives, group size becomes advantageous, which prompts the group's further expansion of its membership. The second finding suggests that adjustment of the sharing rule applied by a group in order to provide stronger incentives to its members might be a prelude to the decline of the group. The revision of the sharing rule could reflect some disorders in the group. Empirical investigation of these predictions is an interesting worthy task for future research. The extent of egalitarianism in our setting is not determined by moral values, religious commitments or social ideology. It is the outcome of rational strategic incentives that arise in the contest environment. In this competitive environment, groups with higher valuation of the prize or larger lobbying capabilities tend to be more egalitarian. Under the sufficient conditions we have stated, larger groups also tend to be more egalitarian. Testing empirically these predictions is another worth pursuing direction.

Finally, we wish to make some remarks on the robustness of the two main results. We have restricted the class of possible group sharing rules to linear combinations between the egalitarian and the relative effort rules. In real interest group politics, a group leader could choose a rule not belonging to this class. But our point is to enable a group to introduce selective incentives and adjust their strength. Even our restrictive feasible set of group sharing rules is sufficient to eliminate the group size paradox. Extension of the range of possible sharing rules would only reinforce the result. Also, with any incentive schemes, it seems plausible to conjecture that a disadvantaged group will provide strong incentives to its members to catch up with the other groups.

Some readers might question the validity of the benevolent leaders 
assumption. Group leaders may maximize the winning probability rather than the per capita utility of their groups to enhance their own benefit. If a leader is a political entrepreneur (Laver (1997)), i.e. an outsider hired by the group members to determine and enforce a group sharing rule, the reward contract might be written conditionally not on the welfare, but on the winning of the group. The former is much more difficult to verify than the latter. In other cases, the competing groups are firms and the leaders are naturally managers. They are responsible for the shareholders, who only care about the success of the firms. In response to such possible criticism, we would like to argue that a group leader cannot do well without the support of the members, and therefore, at least partially he takes care of their welfare. A possible plausible generalization of our model can therefore be based on the assumption that group leaders are concerned both about the winning probability and the welfare of their group. Let the group welfare functions be the averaged utility of the group members, and let $\theta$ and $(1-\theta)$ be the common weights assigned, respectively, to the winning probability and the group welfare in such mixed-motive objective function of the leaders. Then, the following statements can be proved ${ }^{18}$.

- An interior equilibrium sharing rule of the private-good component of the prize of group $i$ is given by

$$
\delta_{i}^{*}=\frac{N_{i}-1+\theta}{(1-\theta)\left(N_{i}-1\right)} \frac{1-\pi_{i}}{\eta\left(N_{i}, \gamma\right)} .
$$

- Proposition 3 holds in this generalized model without any change.

Thus, result (i) is immune to this generalization of the leaders' objectives. From equation (3'), we can observe that the group leaders will choose the pure relative effort rule when $\theta$ is sufficiently close to 1 , i.e. when the leaders' incentives are

\footnotetext{
${ }^{18}$ Notice that a change in the objective functions of group leaders only changes their payoffs in the extensive form of our model. Thus it does not affect Condition 1 of Lemma 1 in Section 6. Also notice that maximization of the winning probability $\pi_{i}$ is equivalent to maximizing $\pi_{i} B\left(\frac{\gamma}{N_{i}}, 1-\gamma\right)$. In turn, instead of Condition 2 of Lemma 1, as the equilibrium condition for the leaders with mixed motives, we would obtain the following expression:

$$
\delta_{i}^{*} \in \underset{0 \leq \delta_{i} \leq 1}{\arg \max } \theta \frac{A_{i}^{*}\left(\delta_{i}\right)}{A} \cdot B\left(\frac{\gamma}{N_{i}}, 1-\gamma\right)+(1-\theta)\left\{\frac{A_{i}^{*}\left(\delta_{i}\right)}{A} \cdot B\left(\frac{\gamma}{N_{i}}, 1-\gamma\right)-v_{i}\left(\frac{A_{i}^{*}\left(\delta_{i}\right)}{N_{i}}\right)\right\} \text {, for all } i=1, \ldots, m .
$$

With this slightly modified condition, we can repeat the proofs of Propositions 1 and 3 to derive the above two statements.
} 
sufficiently solely dependent on the winning probability of their group. As long as the leaders choose interior sharing rules, however, the negative correlation between $\pi_{i}$ and $\delta_{i}^{*}$ is preserved. This implies that result (ii) is also robust.

\section{Proofs}

\section{Proof of Proposition 1.}

We start with a lemma characterizing the equilibria of our model.

Lemma 1. A profile of strategies $\delta_{1}{ }^{*}, \ldots, \delta_{m}{ }^{*}$, and $a_{j h}{ }^{*}\left(\delta_{j}\right)$, for all $j=1, \ldots, m$; $h=1, \ldots, N_{j}$, and $\delta_{j} \in[0,1]$ constitute a pure strategy perfect Bayesian equilibrium with stable belief profiles, if and only if the following two conditions hold:

Condition 1. For all $i=1, \ldots, m ; k=1, \ldots, N_{i}$, and $\delta_{i} \in[0,1], a_{i k}{ }^{*}\left(\delta_{i}\right)=\frac{A_{i}^{*}\left(\delta_{i}\right)}{N_{i}}$ with $\left(1-\frac{A_{i}^{*}\left(\delta_{i}\right)}{A}\right) \cdot B\left(\frac{\gamma}{N_{i}}, 1-\gamma\right)+\gamma \delta_{i} \cdot \frac{\partial B\left(\frac{\gamma}{N_{i}}, 1-\gamma\right)}{\partial q} \cdot\left(1-\frac{1}{N_{i}}\right)-v_{i}{ }^{\prime}\left(\frac{A_{i}^{*}\left(\delta_{i}\right)}{N_{i}}\right) \cdot A=0$,

where $A=\sum_{j \neq i} A_{j}^{*}\left(\delta_{j}^{*}\right)+A_{i}^{*}\left(\delta_{i}\right)$ is the total effort made by the contestants.

Condition 2. $\delta_{i}^{*} \in \underset{0 \leq \delta_{i} \leq 1}{\arg \max } \frac{A_{i}^{*}\left(\delta_{i}\right)}{A} \cdot B\left(\frac{\gamma}{N_{i}}, 1-\gamma\right)-v_{i}\left(\frac{A_{i}^{*}\left(\delta_{i}\right)}{N_{i}}\right)$, for all $i=1, \ldots, m$.

\section{Proof of Lemma 1.}

Only-if-part: Under a stable belief profile, the $k$ th member of group $i$ must choose effort for an arbitrary group sharing rule $\delta_{i}$ that satisfies

$$
a_{i k}^{*}\left(\delta_{i}\right) \in \arg \max _{a \geq 0} \frac{\sum_{h \neq k} a_{i h}^{*}\left(\delta_{i}\right)+a}{\sum_{j \neq i} A_{j}^{*}\left(\delta_{j}^{*}\right)+\sum_{h \neq k} a_{i h}^{*}\left(\delta_{i}\right)+a} B\left[\gamma \cdot\left(\frac{a \cdot \delta_{i}}{\sum_{h \neq k} a_{i h}^{*}\left(\delta_{i}\right)+a}+\frac{1-\delta_{i}}{N_{i}}\right), 1-\gamma\right]-v_{i}(a) .
$$

Since $\lim _{a \rightarrow 0} v_{i}^{\prime}(a)=0$, the maximization problem requires $a_{i k}^{*}\left(\delta_{i}\right)>0$ and the fulfillment of the first order condition:

$$
\begin{aligned}
& \frac{A-A_{i}^{*}\left(\delta_{i}\right)}{A^{2}} \cdot B\left(\gamma \cdot\left(\delta_{i} \cdot \frac{a_{i k}^{*}\left(\delta_{i}\right)}{A_{i}^{*}\left(\delta_{i}\right)}+\left(1-\delta_{i}\right) \cdot \frac{1}{N_{i}}\right), 1-\gamma\right) \\
& \quad+\frac{1}{A} \cdot \gamma \delta_{i} \cdot \frac{\partial B\left(\gamma \cdot\left(\delta_{i} \cdot \frac{a_{i k}^{*}\left(\delta_{i}\right)}{A_{i}^{*}\left(\delta_{i}\right)}+\left(1-\delta_{i}\right) \cdot \frac{1}{N_{i}}\right), 1-\gamma\right)}{\partial q} \cdot \frac{A_{i}^{*}\left(\delta_{i}\right)-a_{i k}^{*}\left(\delta_{i}\right)}{A_{i}^{*}\left(\delta_{i}\right)}-v_{i}{ }^{\prime}\left(a_{i k}^{*}\left(\delta_{i}\right)\right)=0 .
\end{aligned}
$$

As $B$ is concave with respect to the private part of the prize, the left-hand-side of the equation is strictly decreasing with respect to $a_{i k}$. Hence we can confirm that every 
member of group $i$ chooses a symmetric effort level. Condition 1 is therefore established.

Condition 1 implies that $A_{i}^{*}\left(\delta_{i}\right)$ is strictly increasing with respect to $\delta_{i}$. Because of the stability of the belief profile, the leader of group $i$ can change the aggregate effort of the group by a unilateral deviation from the equilibrium group sharing rule $\delta_{i}^{*}$, keeping the effort by the other groups constant. Condition 1 also implies that every member attains a symmetric per capita utility at each value of $\delta_{i}$. The criterion for choosing a group sharing rule is reduced to the maximization of per capita utility, as long as the leader wishes to ensure the selection of a Pareto efficient outcome. Hence Condition 2 is necessary to prevent deviations.

If-part: Let Conditions 1 and 2 hold. By Condition 1, each member of each group maximizes the expected utility over all of his information sets under the stable belief profile. By symmetry and Condition 2, each leader chooses a group sharing rule that maximizes the welfare function of his group, given the sharing rules in the other groups and the succeeding actions of the individual contestants.

Q.E.D.

Part (i) of Proposition 1 is implied by the part of Condition 1 in Lemma 1. We only need to prove part (ii). By the equation (7), $A_{i}{ }^{*}\left(\delta_{i}\right)$ is differentiable with respect to $\delta_{i}$ and $\frac{\partial A_{i}^{*}}{\partial \delta_{i}}>0$. As a necessary and sufficient condition of Condition 2 for group $i$, we therefore have:

$$
\frac{A-A_{i}^{*}\left(\delta_{i}^{*}\right)}{A} \cdot B\left(\frac{\gamma}{N_{i}}, 1-\gamma\right)-v_{i}{ }^{\prime}\left(\frac{A_{i}^{*}\left(\delta_{i}^{*}\right)}{N_{i}}\right) \cdot \frac{A}{N_{i}} \geq(\leq) 0 \text { if } \delta_{i}^{*}>0(<1) .
$$

By equation (7), we can see that $\delta_{i}^{*}=0$ is impossible. Notice that the left-hand side of (8) is strictly decreasing with respect to the value of $A_{i}^{*}$. Therefore, if (8) holds as an equality for some $\delta_{i}<1$, it must be the unique solution and equal to $\delta_{i}^{*}$. Otherwise, the per capita utility is strictly increasing with respect to $\delta_{i}$ on $[0,1]$, and $\delta_{i}^{*}=1$ must hold.

Suppose that group $i$ has an interior group sharing rule $0<\delta_{i}^{*}<1$ in equilibrium. Denoting the winning probability of group $i$ by $\pi_{i}=\frac{A_{i}^{*}\left(\delta_{i}^{*}\right)}{A}$, equation (8) has the form:

$$
\left(1-\pi_{i}\right) \cdot B\left(\frac{\gamma}{N_{i}}, 1-\gamma\right)-v_{i}^{\prime}\left(\frac{A}{N_{i}} \cdot \pi_{i}\right) \cdot \frac{A}{N_{i}}=0 .
$$




\section{Proof of Proposition $2^{19}$.}

Consider, hypothetically, equation (9) as the condition implicitly defining $\pi_{i}$ as a function of $A, \gamma$, and the membership $N_{i}$. Then, $\pi_{i}$ is continuous and strictly decreasing in A. Also, $\lim _{A \rightarrow 0} \pi_{i}=1$ and $\lim _{A \rightarrow \infty} \pi_{i}=0$. As $A$ increases, the value of $\delta_{i}$ derived from equation (3), which is required from Condition 1 and Condition 2 of Lemma 1 as long as $0<\delta_{i}^{*}<1$, approaches 1 . If $\eta\left(N_{i}, \gamma\right)$ is less than $1, \delta_{i}$ satisfying (3) can exceed 1 for the value of $A$ larger than some level, say $A_{R}$. If the total effort $A$ actually attains such a value in an equilibrium, group $i$ must have $\delta_{i}^{*}=1$, and then, $\pi_{i}$ satisfies the equation

$$
\left(1-\pi_{i}\right) \cdot B\left(\frac{\gamma}{N_{i}}, 1-\gamma\right)+\gamma \cdot \frac{\partial B\left(\frac{\gamma}{N_{i}}, 1-\gamma\right)}{\partial q} \cdot\left(1-\frac{1}{N_{i}}\right)-v_{i}^{\prime}\left(\frac{A}{N_{i}} \cdot \pi_{i}\right) \cdot A=0,
$$

which is derived from (7), setting $\delta_{i}=1$. Confirm that $\pi_{i}$ is again continuous and strictly decreasing in $A$ and $\lim _{A \rightarrow \infty} \pi_{i}=0$, when equation (10) is hypothetically seen as the condition defining $\pi_{\mathrm{i}}$ as an implicit function.

Now, consider the share function of group $i$ that depends on $A, \pi_{i}^{P}(A):(0 \infty)$ $\rightarrow \mathbb{R}$, which is defined as follows: for any $A$ in $\left(0, A_{R}\right]$, this function assigns the value of $\pi_{i}$ given by equation (9), and for any $A$ larger than $A_{R}$, it assigns the value of $\pi_{i}$ determined by equation (10). The derived function is continuous and strictly decreasing, with $\lim _{A \rightarrow 0} \pi_{i}^{P}(A)=1$ and $\lim _{A \rightarrow \infty} \pi_{i}^{P}(A)=0$.

Let us consider the value $A^{*}$ with $\sum_{i=1}^{m} \pi_{i}^{P}\left(A^{*}\right)=1$. Such a value certainly exists and is unique. It can be viewed as a candidate of the total equilibrium effort put by all the competing groups. Then, $\pi_{i}^{P}\left(A^{*}\right) A^{*}$ must be the aggregate effort put by group $i$ in equilibrium. By using the definition of the share function and equation (3), we can uniquely specify the group sharing rule $\delta_{i}^{*}$. We can confirm that this rule $\delta_{i}^{*}$ and the aggregate group effort $A_{i}^{*}\left(\delta_{i}^{*}\right)=\pi_{i}^{P}\left(A^{*}\right) A^{*}$ satisfy the conditions of Lemma 1. The existence of equilibrium has thus been confirmed.

On the other hand, if we have an equilibrium with the total equilibrium effort $A^{*}$, Lemma 1 requires that the aggregate effort by group $i$ in equilibrium satisfies $A_{i}^{*}\left(\delta_{i}^{*}\right)=\pi_{i}^{P}\left(A^{*}\right) A^{*}$. In equilibrium, however, the sum of the winning probabilities of

\footnotetext{
${ }^{19}$ We will use the same technique as in Esteban and Ray (2001) and Ueda (2002). This technique is called the share function approach by Cornes and Hartley $(2003,2005)$.
} 
the $m$ groups must be equal to 1 , and $\sum_{i=1}^{m} \pi_{i}^{P}\left(A^{*}\right)=1$ has to be satisfied. This implies the uniqueness of the equilibrium. Q.E.D.

\section{Proof of Proposition 3.}

Keep the total effort unchanged at its equilibrium value $A^{*}$. Pretending that $N_{i}$ is a continuous variable in the equation (9), we can derive from the equation that

$$
\left.\frac{\partial \pi_{i}}{\partial n}\right|_{n=N}=\frac{\pi_{i}}{N} \cdot \frac{1-\eta(N, \gamma)+\alpha\left(\frac{A^{*}}{N} \cdot \pi_{i}\right)}{\frac{\pi_{i}}{1-\pi_{i}}+\alpha\left(\frac{A^{*}}{N} \cdot \pi_{i}\right)} .
$$

If inequality (5) holds, this derivative is positive at all values of $n$ in the closed interval $\left[N, N^{\prime}\right]$. This establishes the validity of Proposition 3.

Q.E.D.

\section{Proof of Proposition 4.}

Again, keeping the total effort unchanged at its equilibrium value $A^{*}$ and viewing $N_{i}$ as a continuous variable, we can examine the behavior of the per capita utility

$$
u_{i}=\pi\left(A^{*}, N_{i}\right) \cdot B\left(\frac{\gamma}{N_{i}}, 1-\gamma\right)-v_{i}\left(\frac{A^{*}}{N_{i}} \cdot \pi\left(A^{*}, N_{i}\right)\right),
$$

where $\pi\left(A^{*}, N_{i}\right)=\pi_{i}$ is the value of the winning probability given by equation (9). By using equations (9) and (11), we get that

$$
\left.\frac{\partial u}{\partial n}\right|_{n=N}=\frac{\pi}{N} \cdot B\left(\frac{\gamma}{N}, 1-\gamma\right) \cdot\left\{1-\eta+\frac{(1-\pi) \pi}{\pi+(1-\pi) \alpha}\left(1-\eta-\frac{\pi}{1-\pi}\right)\right\},
$$

where $\pi=\pi\left(A^{*}, N\right), \quad \alpha=\alpha\left(\frac{A^{*}}{N} \pi\right)$ and $\eta=\eta(N, \gamma)$. If $\inf _{a \geq 0} \alpha(a) \geq 1$ and $0<\pi<\frac{1}{2}$, we can see that $0<\frac{(1-\pi) \pi}{\pi+(1-\pi) \alpha} \leq \frac{1}{4}$ holds. Then, $\max _{n \in\left[N, N^{\prime}\right]} \eta(n, \gamma)<\frac{4}{5}$ implies that $\left.\frac{\partial u}{\partial n}\right|_{n=N}>0$ holds on the interval $\left[N, N^{\prime}\right]$, because

$$
1-\eta+\frac{(1-\pi) \pi}{\pi+(1-\pi) \alpha}\left(1-\eta-\frac{\pi}{1-\pi}\right) \geq 1-\eta+\frac{(1-\pi) \pi}{\pi+(1-\pi) \alpha} \eta \geq 1-\frac{5}{4} \eta
$$

Q.E.D.

\section{Proof of Proposition 5.}

If two groups are symmetric, they have the same schedule of the share function. At the unique equilibrium total effort $A^{*}$, therefore, the groups attain the same values of aggregate group effort. This implies that they have the same group sharing rule, the 
winning probability, and the per-capita utility. When all groups are symmetric, every group attains the winning probability $\frac{1}{m}$, and the equation (6) holds trivially. Q.E.D.

\section{Proof of Proposition 6.}

Equation (9) implies that

$$
\pi_{k} \cdot B\left(\frac{\gamma}{N}, 1-\gamma\right) \cdot \frac{N}{A^{*}}+v_{k}^{\prime}\left(\frac{A^{*}}{N} \cdot \pi_{k}\right)=\pi_{l} \cdot B\left(\frac{\gamma}{N}, 1-\gamma\right) \cdot \frac{N}{A^{*}}+v_{l}^{\prime}\left(\frac{A^{*}}{N} \cdot \pi_{l}\right) .
$$

Suppose that $\pi_{k} \leq \pi_{l}$. We therefore obtain the strict inequality: $v_{k}^{\prime}\left(\frac{A^{*}}{N} \cdot \pi_{k}\right)<v_{l}^{\prime}\left(\frac{A^{*}}{N} \cdot \pi_{l}\right)$, which makes the above equation impossible. This means that $\pi_{k}>\pi_{l}$. Since $\eta\left(N_{k}, \gamma\right)=$ $\eta\left(N_{l}, \gamma\right)=\eta(N, \gamma)$, we can derive $\delta_{k}<\delta_{l}$. Finally, notice that ${A_{k}}^{*}\left(\delta_{k}{ }^{*}\right)$ which maximizes the per capita utility of group $k$, is larger than $A_{l}{ }^{*}\left(\delta_{l}^{*}\right)$. Denoting the per capita utility of group $i$ by $u_{i}$, and noticing that $v_{k}(a)<v_{l}(a)$ for all $a>0$, we get that

$$
\begin{aligned}
u_{k} & =\frac{A_{k}^{*}\left(\delta_{k}^{*}\right)}{A^{*}} \cdot B\left(\frac{\gamma}{N}, 1-\gamma\right)-v_{k}\left(\frac{A_{k}^{*}\left(\delta_{k}^{*}\right)}{N} \cdot\right) \geq \frac{A_{l}^{*}\left(\delta_{l}^{*}\right)}{\sum_{j \neq k} A_{j}^{*}\left(\delta_{j}^{*}\right)+A_{l}^{*}\left(\delta_{l}^{*}\right)} \cdot B\left(\frac{\gamma}{N}, 1-\gamma\right)-v_{k}\left(\frac{A_{l}^{*}\left(\delta_{l}^{*}\right)}{N}\right) \\
& >\frac{A_{l}^{*}\left(\delta_{l}^{*}\right)}{A^{*}} \cdot B\left(\frac{\gamma}{N}, 1-\gamma\right)-v_{k}\left(\frac{A_{l}^{*}\left(\delta_{l}^{*}\right)}{N}\right)>\frac{A_{l}^{*}\left(\delta_{l}^{*}\right)}{A^{*}} \cdot B\left(\frac{\gamma}{N}, 1-\gamma\right)-v_{l}\left(\frac{A_{l}^{*}\left(\delta_{l}^{*}\right)}{N}\right)=u_{l} \cdot \quad \text { Q.E.D. }
\end{aligned}
$$




\section{References}

Baik, Kyung H. 1994. "Winner-Help-Loser Group Formation in Rent-Seeking Contests." Economics and Politics 6 (July): 147-62.

Baik, Kyung H., and Sanghack Lee. 2001. "Strategic Groups and Rent Dissipation." Economic Inquiry 39 (October): 672-84.

Baik, Kyung H., and Sanghack Lee. 2007. "Collective Rent Seeking When Sharing Rules are Private Information.” European Journal of Political Economy 23 (September): 76876.

Chamberlin, John R. 1974. "Provision of Collective Goods as a Function of Group Size." American Political Science Review 68 (June): 707-16.

Cornes, Richard and Roger Hartley. 2003. "Risk Aversion, Heterogeneity and Contests." Public Choice 117(1): 1-25.

Cornes, Richard and Roger Hartley. 2005. "Asymmetric Contests with General Technologies.” Economic Theory 26(4), 923-946.

Epstein, Gil S., and Shmuel Nitzan. 2007. Endogenous Public Policy and Contests. Berlin Heidelberg: Springer-Verlag.

Esteban, Joan-Maria, and Debraj Ray. 2001. "Collective Action and the Group Size Paradox.” American Political Science Review 95 (September): 663-72.

Esteban, Joan-Maria, and Debraj Ray. 2010. “A Model of Ethnic Conflict.” Journal of the European Economic Association. Forthcoming.

Hillman, Arye L. and John G. Riley. 1989. "Politically Contestable Rents and Transfers." Economics and Politics 1 (March): 17-39.

Katz, Eliakim, Shmuel Nitzan, and Jacob Rosenberg. 1990. "Rent-Seeking for Pure Public Goods.” Public Choice 65 (April): 49-60.

Katz, Eliakim, and Julia Tokatlidu. 1996. "Group Competition for Rents.” European Journal of Political Economy 12 (December): 599-607.

Katz, Michael L. 1991. "Game-Playing Agents: Unobservable Contracts as Precommitments.” Rand Journal of Economics 22 (Autumun): 307-28

Konrad, Kai A. 2004. ’Bidding in Hierarchies.” European Economic Review 48 (December): 1301-08.

Konrad, Kai A. 2009. Strategy and Dynamics in Contests. New York: Oxford University Press.

Laver, Michael. 1997. Private Desires, Political Action. London: SAGE Publications Ltd. 
Lee, Sanghack. 1995. "Endogenous Sharing Rules in Collective-Group Rent-Seeking." Public Choice 85 (October): 31-44.

Nitzan, Shmuel. 1991. "Collective Rent Dissipation. Economic Journal 101 (November):1522-34.

Nitzan, Shmuel. 1994. "Transfers or Public Goods Provision? A Political Allocation Perspective." Economics Letters 45 (August): 451-57.

Nitzan, Shmuel, and Kaoru Ueda. 2009. "Collective Contests for Commons and Club Goods." Journal of Public Economics, 93 (1), 48-55.

Olson, Mancur. 1982. The Rise and Decline of Nations. New Haven and London: Yale University Press.

Riaz, Khalid, Jason F. Shogren and Stanley R. Johnson. 1995. “A General Model of RentSeeking for Public Goods.” Public Choice 82 (March): 243-59.

Sen, Amartya K. 1966. "Labour Allocation in a Cooperative Enterprise." Review of Economic Studies 33 (October): 361-71.

Ueda, Kaoru. 2002. "Oligopolization in Collective Rent-Seeking." Social Choice and Welfare 19 (July): 613-26.

Ursprung, Heinrich W. 1990. "Public Goods, Rent Dissipation, and Candidate Competition.” Economics and Politics 2 (July): 115-132.

Wärneryd, Karl. 1998. “Distributional Conflict and Jurisdictional Organization.” Journal of Public Economics 63(September): 435-450. 


\section{CESifo Working Paper Series}

for full list see www.cesifo-group.org/wp

(address: Poschingerstr. 5, 81679 Munich, Germany, office@cesifo.de)

3148 Ilja Neustadt and Peter Zweifel, Is the Welfare State Sustainable? Experimental Evidence on Citizens’ Preferences for Redistribution, August 2010

3149 Marcus Dittrich and Andreas Knabe, Wage and Employment Effects of Non-Binding Minimum Wages, August 2010

3150 Shutao Cao, Enchuan Shao and Pedro Silos, Fixed-Term and Permanent Employment Contracts: Theory and Evidence, August 2010

3151 Ludger Woessmann, Cross-Country Evidence on Teacher Performance Pay, August 2010

3152 Lorenzo C. G. Pozzi, Casper G. de Vries and Jorn Zenhorst, World Equity Premium Based Risk Aversion Estimates, August 2010

3153 Volker Grossmann, Thomas M. Steger and Timo Trimborn, Dynamically Optimal R\&D Subsidization, August 2010

3154 Alexander Haupt, Tim Krieger and Thomas Lange, A Note on Brain Gain and Brain Drain: Permanent Migration and Education Policy, August 2010

3155 António Afonso and Christophe Rault, Long-run Determinants of Sovereign Yields, August 2010

3156 Franziska Tausch, Jan Potters and Arno Riedl, Preferences for Redistribution and Pensions. What can we Learn from Experiments?, August 2010

3157 Martin Kolmar and Andreas Wagener, Inefficient Group Organization as Optimal Adaption to Dominant Environments, August 2010

3158 Kai Carstensen, Klaus Wohlrabe and Christina Ziegler, Predictive Ability of Business Cycle Indicators under Test: A Case Study for the Euro Area Industrial Production, August 2010

3159 Horst Rottmann and Timo Wollmershäuser, A Micro Data Approach to the Identification of Credit Crunches, August 2010

3160 Philip E. Graves, Appropriate Fiscal Policy over the Business Cycle: Proper Stimulus Policies Can Work, August 2010

3161 Michael Binder and Marcel Bluhm, On the Conditional Effects of IMF Program Participation on Output Growth, August 2010

3162 Michael Binder, Qianying Chen, and Xuan Zhang, On the Effects of Monetary Policy Shocks on Exchange Rates, August 2010 
3163 Felix J. Bierbrauer, On the Optimality of Optimal Income Taxation, August 2010

3164 Nikolaus Wolf, Europe’s Great Depression - Coordination Failure after the First World War, September 2010

3165 Dan Kovenock and Brian Roberson, Conflicts with Multiple Battlefields, September 2010

3166 Jean-Pierre Ponssard and Catherine Thomas, Capacity Investment under Demand Uncertainty. An Empirical Study of the US Cement Industry, 1994-2006, September 2010

3167 Jørgen Juel Andersen, Jon H. Fiva and Gisle James Natvik, Voting when the Stakes are High, September 2010

3168 Michael Hoel, Is there a Green Paradox?, September 2010

3169 Scott Alan Carson, Nineteenth Century US African-American and White Female Statures: Insight from US Prison Records, September 2010

3170 Gil S. Epstein, Yosef Mealem and Shmuel Nitzan, Political Culture and Discrimination in Contests, September 2010

3171 Sara Fisher Ellison, Jeffrey Greenbaum and Wallace P. Mullin, Diversity, Social Goods Provision, and Performance in the Firm, September 2010

3172 Silvia Dominguez-Martinez, Randolph Sloof and Ferdinand von Siemens, Monitoring your Friends, not your Foes: Strategic Ignorance and the Delegation of Real Authority, September 2010

3173 Marcus Dittrich and Beate Schirwitz, Union Membership and Employment Dynamics: A Note, September 2010

3174 Francesco Daveri, Paolo Manasse and Danila Serra, The Twin Effects of Globalization - Evidence from a Sample of Indian Manufacturing Firms, September 2010

3175 Florian Blöchl, Fabian J. Theis, Fernando Vega-Redondo and Eric O’N. Fisher, Which Sectors of a Modern Economy are most Central?, September 2010

3176 Dag Morten Dalen, Marilena Locatelli and Steinar Strøm, Longitudinal Analysis of Generic Substitution, September 2010

3177 Armin Falk, Stephan Meier and Christian Zehnder, Did we Overestimate the Role of Social Preferences? The Case of Self-Selected Student Samples, September 2010

3178 Christian Fahrholz and Cezary Wójcik, The Bail-Out! Positive Political Economics of Greek-type Crises in the EMU, September 2010

3179 Klaus Abberger and Wolfgang Nierhaus, The Ifo Business Cycle Clock: Circular Correlation with the Real GDP, September 2010 
3180 Walter Krämer and Gerhard Arminger, “True Believers” or Numerical Terrorism at the Nuclear Power Plant, September 2010

3181 Bernard M.S. Van Praag, Dmitri Romanov and Ada Ferrer-i-Carbonell, Happiness and Financial Satisfaction in Israel. Effects of Religiosity, Ethnicity, and War, September 2010

3182 Dimitrios Koumparoulis and Paul De Grauwe, Public Capital, Employment and Productivity: An Empirical Investigation for Greece, September 2010

3183 John Whalley and Tanmaya Shekhar, The Rapidly Deepening India-China Economic Relationship, September 2010

3184 Andreas Schäfer and Thomas Steger, History, Expectations, and Public Policy: Economic Development in Eastern Germany, September 2010

3185 Thomas Eichner and Marco Runkel, Subsidizing Renewable Energy under Capital Mobility, September 2010

3186 Konstantinos Angelopoulos and James Malley, Fear of Model Misspecification and the Robustness Premium, September 2010

3187 Philip E. Graves, A Note on the Design of Experiments Involving Public Goods, September 2010

3188 Glenn Ellison, How does the Market Use Citation Data? The Hirsch Index in Economics, September 2010

3189 Barbara Hanel and Regina T. Riphahn, The Employment of Mothers - Recent Developments and their Determinants in East and West Germany, September 2010

3190 Alexander Haupt and Silke Uebelmesser, Integration, Mobility, and Human Capital Formation, September 2010

3191 Vincenzo Galasso and Paola Profeta, When the State Mirrors the Family: The Design of Pension Systems, September 2010

3192 Stéphane Zuber and Geir B. Asheim, Justifying Social Discounting: The RankDiscounted Utilitarian Approach, September 2010

3193 Alexander Kemnitz, Educational Federalism and the Quality Effects of Tuition Fees, September 2010

3194 Claudia M. Buch, Sandra Eickmeier and Esteban Prieto, Macroeconomic Factors and Micro-Level Bank Risk, September 2010

3195 May Elsayyad and Kai A. Konrad, Fighting Multiple Tax Havens, September 2010

3196 Laszlo Goerke and Markus Pannenberg, Trade Union Membership and Dismissals, September 2010 
3197 Ferdinand Mittermaier and Johannes Rincke, Do Countries Compensate Firms for International Wage Differentials?, September 2010

3198 John Boyd, Gianni De Nicoló and Abu M. Jalal, Bank Competition, Asset Allocations and Risk of Failure: An Empirical Investigation, September 2010

3199 Guido Heineck and Bernd Süssmuth, A Different Look at Lenin’s Legacy: Trust, Risk, Fairness and Cooperativeness in the two Germanies, September 2010

3200 Ingvild Almås, Tarjei Havnes and Magne Mogstad, Baby Booming Inequality? Demographic Change and Earnings Inequality in Norway, 1967-2000, October 2010

3201 Thomas Aronsson and Sören Blomquist, The Standard Deviation of Life-Length, Retirement Incentives, and Optimal Pension Design, October 2010

3202 Thorvaldur Gylfason and Eduard Hochreiter, Growing Together: Croatia and Latvia, October 2010

3203 Ken Burdett and Melvyn Coles, Tenure and Experience Effects on Wages: A Theory, October 2010

3204 Wendy Carlin, Good Institutions are not enough: Ongoing Challenges of East German Development, October 2010

3205 Tobias König and Andreas Wagener, Tax Structure and Government Expenditures under Tax Equity Norms, October 2010

3206 Daniel W. Sacks, Betsey Stevenson and Justin Wolfers, Subjective Well-Being, Income, Economic Development and Growth, October 2010

3207 Mario Larch and Wolfgang Lechthaler, Why "Buy American” is a Bad Idea but Politicians still Like it, October 2010

3208 Guglielmo Maria Caporale and Luis A. Gil-Alana, US Disposable Personal Income and Housing Price Index: A Fractional Integration Analysis, October 2010

3209 Bruno S. Frey, Withering Academia?, October 2010

3210 Eva Mörk, Anna Sjögren and Helena Svaleryd, Childcare Costs and the Demand for Children - Evidence from a Nationwide Reform, October 2010

3211 Dan Kovenock, Brian Roberson and Roman M. Sheremeta, The Attack and Defense of Weakest-Link Networks, October 2010

3212 Shmuel Nitzan and Kaoru Ueda, Prize Sharing in Collective Contests, October 2010 